\title{
Construindo caminhos de conhecimentos em HIV/Aids: mulheres em cena
}

\section{| ${ }^{1}$ Girlene Alves Silva, ${ }^{2}$ Valesca Nunes dos Reis |}

Resumo: Trata-se de pesquisa qualitativa com o objetivo de identificar o acesso à informação das mulheres sobre o HIV/Aids e analisar os fatores que as orientam na adoção de medidas protetoras ao HIV/Aids. Foram realizadas entrevistas com 20 mulheres matriculadas no período noturno de uma escola pública em Minas Gerais/Brasil, com faixa etária entre 18 e 55 anos. As entrevistas foram analisadas por meio da técnica de análise de conteúdo temático, e fundamentadas no referencial teórico das Representações Sociais. Foram produzidas duas categorias analíticas: o acesso à informação sobre a Aids e os mecanismos de proteção adotados para reduzir a vulnerabilidade à infecção pelo HIV. As entrevistadas apontaram escola, família, televisão, profissionais de saúde e amigos como os principais veículos de obtenção de informações acerca da Aids. Entretanto, nesses espaços e encontros o vínculo se encontra fragilizado, desfragmentado e inconsistente, não propiciando acesso a ambientes consistentes de escuta, informaçōes e reflexões. A prevenção está focada no uso do preservativo masculino. Persiste o baixo poder da mulher em negociar relaçóes sexuais seguras, prevalecendo a vontade do parceiro e a credibilidade no amor e no casamento. Os sentimentos de ansiedade, incertezas e medo gerados nessas mulheres devido à questão da Aids não lhes permitem efetivar mecanismos de proteção relacionados ao exercício de mudança no comportamento sexual, de forma a torná-lo mais seguro e consciente no grupo pesquisado.

> Palavras-chave: Síndrome de imunodeficiência adquirida; vulnerabilidade; mulheres; prevenção de doenças.

\footnotetext{
1 Professora associada do Departamento de Enfermagem Aplicada da Faculdade de Enfermagem da Universidade Federal de Juiz de Fora (UFJF). Endereço eletrônico: girlas@ terra.com.br

${ }^{2}$ Mestre em Saúde Coletiva; enfermeira do Hospital Universitário da UFJF. Endereço eletrônico: valesca.nr@gmail.com
} 
Há três décadas, a trajetória da Aids (Acquired Immunodeficiency Syndrome) começou a ser delineada na história da humanidade e, desde então, vários caminhos continuam sendo traçados em torno deste fenômeno, demonstrando seu caráter dinâmico, complexo e multidimensional. A doença adquiriu rapidamente, a partir de sua identificação em 1981 (ROUQUAYROL; ALMEIDA, 2003), dimensão epidêmica, afastando qualquer possibilidade de se configurar como um processo estático, linear e estanque.

A epidemia, que inicialmente atingiu os homossexuais urbanos com alta escolaridadeeusuáriosdedrogasinjetáveis, deslocou-separagruposheterossexuais de menor faixa etária, para o sexo feminino, segmentos populacionais com baixo nível de escolaridade e baixa renda e que residem em municípios de médio e pequeno porte (FONSECA et al., 2002; SZWARCWALD et al., 2000; XAVIER et al., 1997). Essa mudança no perfil epidemiológico gerou a construção dos conceitos de heterossexualização, feminização, pauperização e interiorização (GRANJEIRO et al., 2010; SZWARCWALD; BASTOS, 2000; TOMAZELLI et al., 1997).

No Brasil, a dinâmica da Aids vem expressando as tendências internacionais, impondo desafios ao desenvolvimento e ao progresso social do país. O aumento da transmissão nas relações heterossexuais, que hoje representa no país a principal via de contaminação entre as mulheres, implicou, evidentemente, a elevação dos casos de HIV/Aids na população feminina (SZWARCWALD et al., 2000). A epidemia apresenta-se estável e concentrada em alguns subgrupos populacionais em situação de vulnerabilidade.

De acordo com o último Boletim Epidemiológico (ano base 2010), foram notificados (SINAN, SIM, SISCEL/SICLOM) 608.230 casos de Aids acumulados de 1980 a junho de 2011, sendo que, destes, 397.662 (65,4\%) são do sexo masculino e 210.538 (34,6\%) do sexo feminino. A razão entre os sexos vem diminuindo ao longo dos anos. Em 1985, para cada 26 casos entre homens, havia um caso no segmento feminino. Em 2010, essa relação é de 1,7 homens para cada caso em mulheres. A taxa de prevalência da infecção pelo HIV, na população de 15 a 49 anos, mantém-se estável em 0,6\% desde 2004, sendo 0,4\% entre as mulheres e $0,8 \%$ entre os homens (BRASIL, 2011). 
É importante ressaltar que se observa tendência de aumento na prevalência da infecção pelo HIV nos jovens. Com relação às taxas de incidência de Aids entre jovens de 15 a 24 anos em 2010, a taxa para os homens foi de dois casos de Aids e para as mulheres foi de 1,6 casos para cada 100 mil habitantes. No que diz respeito à razão de sexos, nessa faixa etária observa-se que nos últimos 20 anos também ocorreu redução na proporção de casos entre homens e mulheres (BRASIL, 2011). Alguns estudos comprovam que as mulheres se encontram em desvantagem no que se refere à prevenção, controle e tratamento da doença, tornando-se mais vulneráveis à infecção pelo HIV (TOMAZELLI et al., 2003; PARKER et al., 2000; TAKAHASHI et al., 1998).

A feminização da epidemia no Brasil ocorreu de forma clara e rápida, principalmente devido ao silêncio e omissão dos órgãos governamentais responsáveis pela formulação de programas - fato agravado pelo não-entendimento das múltiplas origens que compõem as vulnerabilidades femininas perante a contaminação pelo HIV na sociedade brasileira (PARKER; GALVÃO, 1996). A crença de que as mulheres estavam imunes ao risco de contaminação pelo HIV, associada a diagnósticos tardios e errados, ou mesmo à ausência destes, contribuiu primariamente para a ampla disseminação da Aids no segmento feminino (MARQUES et al., 2007; BARBOSA; VILLELA, 1996). Diante desse contexto foi publicado, em 2007, o Plano Integrado de Enfrentamento à Feminização da Epidemia da Aids e outras DST, por meio do Programa Nacional de DST e Aids e da Área Técnica de Saúde da Mulher. Este plano tem como escopo principal enfrentar a feminização da epidemia do HIV/Aids e outras DST por meio da redução das vulnerabilidades que atingem as mulheres, estabelecendo políticas de prevenção, promoção e atenção integral (BRASIL, 2007).

Esse cenário evidencia a necessidade de contribuir com a identificação de elementos essenciais à definição das especificidades regionais e culturais no que se refere às representações das mulheres em relação à Aids, no sentido de desenhar e caracterizar particularidades estruturais e conjunturais do contexto no qual a epidemia se dissemina. Elencar as peculiaridades locais no controle da epidemia no Brasil torna-se efetivo quando se parte da premissa que desvendar a realidade epidemiológica de determinados grupos e cidades servirá para subsidiar a construção de políticas públicas conforme o perfil dos municípios onde as 
estratégias preventivas devem considerar a inter-relação entre as diferentes formas de transmissão (GRANGEIRO et al., 2010).

$\mathrm{Na}$ perspectiva de contribuir com a identificação de elementos essenciais à definição dos padrões de incidência e de evolução da Aids no Brasil, desenvolvemos este estudo, que visou compreender o comportamento feminino acerca de suas vulnerabilidades frente à Aids no município de Juiz de Fora. $\mathrm{O}$ artigo tem como objetivos identificar os espaços onde as mulheres acessam as informaçóes sobre o HIV/Aids e analisar os fatores que as orientam na adoção de medidas protetoras ao HIV/Aids.

\section{O caminho teórico e metodológico}

Em busca da compreensão da resposta social perante a Aids, o referencial teórico das Representaçóes Sociais representou o fio condutor desta pesquisa, pois permite reconhecer e comunicar um fenômeno social particular, de forma a tornálo inteligível como processo sociopsicológico. Desse modo, com base na Teoria das Representações Sociais (TRS), buscou-se analisar os saberes das mulheres em relação ao HIV/Aids e as medidas protetoras de redução da vulnerabilidade.

As Representações Sociais são uma forma de saber de senso comum que busca compreender e comunicar as crenças, imagens, símbolos, valores e atitudes compartilhados coletiva e conscientemente em um grupo, sociedade ou cultura (WAGNER, 2000; MOSCOVICI, 2003). Para Jodelet (2001, p. 21), as representações são "fenômenos complexos sempre ativados e em ação na vida social”. Estudar as representações sociais da Aids no universo jovem feminino é buscar compreender como essas mulheres, em suas interaçôes sociais, decodificam e assimilam as questôes postas pela complexidade desses fenômenos, sobretudo as relacionadas aos aspectos da prevenção. Além disso, permite apreender os processos e mecanismos pelos quais esse grupo de mulheres constrói o sentido desta epidemia em suas realidades cotidianas. Evidencia, assim, condutas e práticas adotadas e compartilhadas pelos sujeitos - estas representativas da afirmação simbólica de pertença e identidade.

Portanto, estudar as representações sociais sobre a epidemia do HIV/Aids significa entender como os grupos e os indivíduos pensam e se relacionam com esse fenômeno em sua totalidade e seu dinamismo. É procurar identificar, nos sujeitos, as representações que lhes são inerentes e assim descobrir o que revelam exatamente. 
Tendo os pressupostos da TRS como base teórica, optou-se pelo método

de investigação qualitativa do tipo descritivo e analítico para realização deste estudo, uma vez que esse método é caracterizado como a tentativa de compreender em detalhes os significados e características situacionais apresentados pelos sujeitos investigados.

A pesquisa teve como cenário uma Escola Pública do município de Juiz de Fora-MG. O início da entrada no campo em busca dos dados ocorreu nos meses de agosto e setembro de 2009, após aprovação pelo Comitê de Ética em Pesquisa (CEP) da Universidade Federal de Juiz de Fora (protocolo no 1692.036.2009) e anuência da Direção da Escola.

Constituíram sujeitos do estudo 20 mulheres matriculadas no período noturno, com idade igual ou superior a 18 anos de idade, que aceitaram participar do estudo e assinaram o termo de consentimento livre e esclarecido, elaborado de acordo com as recomendações da Resolução no 196/96 do Conselho Nacional de Saúde. O anonimato dessas mulheres foi garantido pela utilização de nomes fictícios.

De acordo com esses dados, ressaltamos que das 20 mulheres entrevistadas 14 encontravam-se na faixa etária dos 18 aos 24 anos, cinco na faixa dos 25 aos 35 anos e uma na faixa dos 36 aos 60 anos. A idade média das entrevistadas foi de 24 anos com uma mediana de 22 anos, sendo a maior idade de 55 anos e mínima de 18 anos. Em relação ao estado civil, 14 das informantes afirmaram ser solteiras, cinco casadas, uma viúva e uma diz manter uma união consensual.

Do total dos sujeitos, $45 \%$ têm filhos, e uma encontrava-se grávida. A maioria (65\%) das entrevistadas estava cursando o ensino fundamental, enquanto $35 \%$ cursavam o ensino médio. Quando questionadas sobre desenvolverem alguma atividade remunerada, apenas três mulheres enquadravam-se no grupo da população economicamente ativa, e as outras 17 estavam desempregadas no momento em que a entrevista foi realizada. Entre as ocupações, foram citadas doméstica, secretária e manicure.

Os dados da pesquisa foram apreendidos por meio da técnica de entrevista. As entrevistas foram agendadas e realizadas individualmente de acordo com o horário definido pela entrevistada, de modo a não prejudicar o andamento das atividades escolares. Ressalta-se que todas as entrevistas foram realizadas na escola no turno noturno e gravadas em fitas magnéticas. As informações apreendidas foram submetidas à análise de conteúdo temático. Para Bardin 

a uma afirmação sobre determinado assunto, sendo o termo frequentemente utilizado como unidade de registro nos estudos de valores, crenças, atitudes, etc.

A técnica de análise temática nos permitiu definir os temas do estudo, que receberam a seguinte denominação: mulheres desenhando o acesso à informação sobre a Aids; pensando e fazendo prevenção: mulheres reduzindo a vulnerabilidade ao HIV/Aids.

\section{Apresentação e discussão dos resultados \\ Mulheres desenhando o acesso à informação sobre a Aids}

Acerca do acesso as informações sobre a Aids, identificamos que a maioria das informações que elas dizem acessar encontra a escola como espaço de mediação desses saberes, mas nem sempre o tema Aids faz parte do conteúdo do projeto político-pedagógico-metodológico da própria escola, mas sim de outras instituiçóes de ensino que esporadicamente utilizam o campo da escola como espaço de aprendizado, como podemos perceber nos discursos abaixo:

Foi uma palestra [...]. Foi uma enfermeira que veio com as alunas aqui [...]. Não, com os professores é muito difícil. (Maria Aparecida)

Aliás, tiveram sim, duas palestras aqui [...]. Pessoal lá, daquela faculdade nova [...]. Tiveram duas palestras. (Maria Luiza)

A professora de biologia, a X, no terceiro ano a gente estuda sobre isso. Ela é uma professora excelente, ela fala abertamente sobre essa parte e questão em geral, ela fala sobre esperma, sobre o óvulo, ela fala tudo sobre isso [...]. Teve a palestra no começo do ano da Faculdade W [...] Eles falaram sobre sexualidade. Aí não foi concretizada a palestra, porque veio a greve, então eu acho que eles desanimaram um pouco justamente por isso, né? Acho que a intenção era de continuar a palestra nesse quesito de sexualidade e mostrar isso que você está mostrando para gente também. (Maria Isabel)

Os professores que falam alguma coisa, né! Alguma coisa ou outra que sai. Mas assim, parar para conversar, igual você está fazendo agora, não teve não. Teve palestra lá em cima, mas foi assim todo mundo, não foi uma coisa exclusiva só não, foi todo mundo. (Maria Maria)

Depreendemos da análise das falas que a palestra, como técnica e método de ação, se configura como o principal veículo propagador de informaçōes sobre a Aids entre os "detentores" do saber e seus receptores. A abordagem foca-se na reprodução de conhecimentos técnico-científicos, de forma passiva e pouco interativa. Esse tipo de intervenção na esfera das práticas educativas não favorece 
a aquisição de comportamentos sexuais seguros e responsáveis, que visem à busca pelo bem-estar e qualidade de vida.

Na mesma linha de pensamento, Ayres (2002) pontua que constitui um desafio nas práticas educativas o rompimento de atitudes modeladoras de comportamentos, substituindo-as por atitudes emancipadoras, ou seja, deixar de ser detentor do saber e passar a ser mediador para o saber. Essa mudança de atitude por parte dos educadores favorece a simetria entre estes e os educandos, criando o ambiente adequado para o compartilhamento de problemáticas e a criatividade individual e coletiva na busca de soluçōes.

Castro, Abramovay e Silva (2004, p. 105) afirmam que "as palestras, enquanto atividades planejadas ou trabalhos isolados, tornam-se alvo de críticas pela falta de continuidade e monotonia que impõem aos alunos". Na mesma perspectiva, Amaro (2005) levanta uma crítica às palestras como atividade educativa de prevenção mais utilizada, à medida que esta pouco impacta "na modificação de condutas e autocuidado, quando se trata do segmento feminino, historicamente alijado nesse foco pelo tabu que ainda impera" (2005, p. 93).

É imperativo estimular, nas instituições de ensino, o oferecimento de informações claras sobre as DST/Aids por professores qualificados e capacitados sobre o tema, através de uma abordagem que valorize e respeite os aspectos sociais e psicológicos dos alunos, com vistas a oportunizar a aquisição de habilidades para trabalhar com questôes relacionadas à sexualidade (ARRUDA; CAVASIN, 2000).

Outra fonte de informação apontada em uma das entrevistas fez referência à televisão:

A primeira vez que eu ouvi falar sobre esse assunto mesmo, ou foi na televisão que de vez em quando aparece lá e aqui no colégio, né? (Maria do Socorro).

Esse veículo de comunicação foi, desde o início da epidemia, estratégico na divulgação de questões relacionadas à Aids. Porém, é mister relembrar que a mídia televisiva foi uma das responsáveis pela disseminação de um imaginário "alarmista" em torno da Aids, ao estimular o preconceito e a discriminação através do enfoque de grupo e comportamento de risco, fortalecendo a ideia de que o portador do vírus HIV está incondicionalmente destinado a morrer.

Nos dias atuais, os meios de comunicação, principalmente a televisão, ocupam papel relevante no que se refere à influência na formação e orientação de jovens e adolescentes em relação aos aspectos envolvidos com o HIV/Aids, 
muitas vezes desempenhando o papel de educador sexual que deveria ser exercido pela escola e/ou família.

A escola, para as mulheres participantes deste estudo, se configura como um ambiente privilegiado de trocas de saberes, pois é também na escola que as amigas trocam informações baseadas em suas experiências de vida. Os depoimentos a seguir colocam as relações de amizades como oportunidades de discussão das informaçōes sobre a Aids:

Com as minhas amigas é fácil, né?, de falar. (Maria da Conceição)

[...] tem os conselhos e alguns conselhos que a gente pede [...]. Porque às vezes as meninas são mais experientes do que eu, são casadas. (Maria Augusta)

Elas ficam falando algumas coisas assim, temas assim, ai fala, elas comentam como é que foi como é que não foi [...] A primeira vez delas [...] Quando elas ficam grávidas elas passam para gente que ficaram grávidas. Sempre, a mesma desculpa que a camisinha estourou. Sempre usam essa desculpa. (Maria Carmem)

Nos relatos, credibilidade é dada pelas informantes às mulheres casadas, com experiência reprodutiva e idade cronológica superior, como sendo as mais habilitadas para oferecerem conselhos e compartilhar as experiências particulares. A prevenção, quando surge nos diálogos entre elas, é no sentido de não permitir uma gravidez indesejada, sem que este termo se referencie às DST/Aids. É portanto, no aspecto reprodutivo, que estão centralizadas as representações dessas mulheres quando pensam em prevenção.

É oportuno considerar que nas conversas entre as amigas o enfoque é dado ao ato sexual, cujo teor tem como objetivo satisfazer as curiosidades acerca das experiências vivenciadas por essas mulheres em suas relaçōes, de forma a torná-las mais prazerosas. A autopercepção de vulnerabilidade para DST/Aids não parece ser um dos motivos que levam essas mulheres a buscarem apoio e/ou conselhos das amigas quanto a suas práticas sexuais.

As mulheres também buscam informações e orientações junto aos profissionais na unidade básica de saúde do bairro, como representam os seguintes recortes:

A minha mãe me ensinou que sempre que eu tiver uma relação é para eu ir ao posto médico. [...] E na minha primeira vez eu vou no posto pedir orientação. (Maria José)

Porque eu fui numa reunião que estava acontecendo no posto de saúde e lá eles ensinaram um pouco, para a gente poder pegar o remédio. (Maria de Fátima)

A gente tem que pedir uma orientação ao médico sobre como não pegar esse vírus. (Maria Cristina) 
Apesar de os serviços de saúde serem espaços privilegiados na mediação da promoção à saúde, essa referência no presente estudo aparece nos discursos de apenas três mulheres. Corrobora esse achado o estudo desenvolvido por Bozon e Heilborn (2006), que destaca que a frequência com que os serviços de saúde foram mencionados por mulheres jovens, como fonte de informação para o aprendizado de suas sexualidades, foi reduzida, e que em três capitais brasileiras pesquisadas, o índice não ultrapassou os $17 \%$.

Essa situação dá margem à reflexão de que há um inexistente ou ineficaz diálogo entre a escola e os serviços de saúde. Partimos da premissa de que uma das perspectivas possíveis para permitir e/ou ampliar a compreensão adequada sobre o fenômeno Aids pelo segmento feminino deve primar pela aproximação entre as diversas instituições sociais que tenham como princípios a educação e a prevenção. Portanto, para se promover a saúde integral, bem-estar e desenvolvimento saudável dos sujeitos, de forma a reduzir os índices de morbi-mortalidade e os desajustes individuais e sociais, objetivos definidos coletivamente através da articulação entre pessoas e instituições são um meio de encontrar saídas para intervir na realidade social complexa e multifacetada imposta pela dinâmica do HIV/Aids no segmento feminino.

As mulheres deste estudo também colocam a família como orientadora no campo da promoção à saúde.

Minha mãe conversa, ela é conversativa. [...] sobre doença, gravidez, minha mãe é bem liberada nesse ponto. (Maria da Conceição)

A mãe aparece como a única referência familiar que oportuniza um espaço para abertura de um diálogo, mesmo que este não signifique uma fonte imediata de informação correta. Porém, mesmo que possa sentir-se incapaz de fornecer o acolhimento adequado a seu filho, por não deter conhecimento suficiente sobre temas correlatos à sexualidade, a mãe o orienta a buscar os locais que ela acredita serem os mais apropriados para instrumentalizá-lo na tomada de decisões afetivosexuais mais conscientes e protetoras.

Estudo realizado por Cruzeiro et al. (2010) sinaliza que há uma relação direta entre o nível de escolaridade da mãe e o uso do preservativo, ou seja, quanto menor o grau de escolaridade da mãe, menor a adesão ao uso do preservativo pelo filho(a) nas relações sexuais. Ressalta que a família representa uma fundamental fonte de informação para os adolescentes, e que, portanto, uma mãe com elevado 
grau de escolaridade amplia a possibilidade de transmissão de informação de qualidade sobre sexualidade aos filhos.

Consoante com essa análise, pensamos que a família poderia ser a fonte primeira de informação, apoio e diálogo no campo da sexualidade, da promoção da saúde e suas interfaces com a prevenção de doenças. Pode-se inferir, porém, que existem diversos fatores sociais e culturais que dificultam o estabelecimento e fortalecimento da relação pais-filhos nesse contexto de discussão e informação.

A dificuldade em estabelecer esse vínculo pode ser motivada pela insegurança e incapacidade, por parte dos pais, de gerar informação correta e consistente a seus filhos; diferenças geracionais conservadoras apoiadas em valores, princípios e regras; ausência de intimidade entre pais e filhos; crença, por parte dos pais, de que dialogar sobre este tema é responsabilidade apenas da escola; tempo de permanência e convivência com os filhos reduzido, ocasionado por uma lógica capitalista pautada no consumismo e individualismo.

\section{Pensando e fazendo prevenção: mulheres reduzindo a vulnerabilidade ao HIV/Aids}

É no preservativo masculino que nossas entrevistadas centralizam a ideia de prevenção ao HIV. Ele representa para elas o único e/ou principal mecanismo capaz de impedir que a Aids passe a fazer parte de suas vidas. Os recortes das entrevistas a seguir mostram que o preservativo constitui uma barreira importante de redução da vulnerabilidade ao HIV:

Tem que usar camisinha, né? [...] Eu uso só a camisinha, mas esses outros negócios, se tem outras coisas, eu não sei para prevenir a doença. (Maria Aparecida)

O que está mais ao alcance da gente é a camisinha mesmo, né? (Maria Luiza)

[...] como prevenir, eu sei, usando preservativo, é ter um parceiro só. (Maria Fernanda)

Camisinha, preservativo [...] porque nem vacina tem ainda, né? (Maria Laura)

O método é a camisinha. [...] Porque tem momentos assim, se ele está naquela vontade daí a gente esquece, nem sempre ele está na carteira. (Maria Augusta)

E camisinha ele não usa. Ele odeia camisinha [...] Eu usei uma vez, mas mesmo assim a gente não terminou. A gente começou a usar daí não deu em nada, ele não gostou e a gente jogou fora. [...] Eu até briguei com ele esses dias e falei que só ia transar com ele com camisinha, sem camisinha eu não transo. Aí ele correu o guarda-roupa para ver se achava uma camisinha e achou uma lá de 2004/2005... Só que a gente não usou não. (Maria Célia) 
Podemos inferir que essas mulheres percebem que a responsabilidade pelo enfrentamento da doença e do contágio ao HIV é individual, instituído pelo cuidado preventivo, através do uso do preservativo masculino. Contudo, uma das mulheres também reconhece na atividade sexual praticada com parceiro fixo uma via de prevenção. O preservativo masculino aparece como o principal mecanismo de prevenção nas representações das mulheres, mas o fato de ele aparecer no discurso não garante seu uso consistente e contínuo por parte de quem faz apologia a essa prática.

Nessa perspectiva, Aboim (2012) sublinha que o fato de um indivíduo perceber que está em risco de se infectar, seja pelo vírus HIV ou qualquer outra doença sexualmente transmissível, parece não direcioná-lo linearmente ao uso do preservativo. Pontua ainda que o ato decisório do uso ou não do preservativo perpassa obrigatoriamente a relação estabelecida entre o casal, através de estratégias que são elaboradas reflexiva e antecipadamente diante do medo de adquirir uma doença transmitida pela via sexual. E assinala que são as mulheres de perfil monogâmico e envolvidas em relacionamentos conjugais as que menos se previnem contra eventuais riscos de transmissão.

Estudo realizado por Antunes et al. (2002) indicou que as mulheres apresentam maior dificuldade para negociar o uso do preservativo e vergonha de falar para o parceiro sobre as práticas que lhes dão mais prazer, além de associarem com maior frequência o sexo com amor. Diante da insistência do parceiro para praticar o ato sexual desprotegido, a mulher acaba cedendo e satisfazendo sua vontade, mesmo se sentindo insegura, amedrontada e internamente ciente do risco assumido. Isto se deve principalmente à dificuldade que a mulher apresenta de assumir posturas firmes e decisivas na utilização do preservativo, revelando mais uma vez seu baixo poder de negociação de estratégias de prevenção frente ao HIV/Aids. Desconfiar estar sob risco, e mesmo assim não decidir pelo uso do preservativo, revela um sentimento de impotência e submissão diante do desejo do parceiro.

A sexualidade e as práticas sexuais são, em grande medida, modeladas culturalmente, apresentando-se como hábitos, prescrições e normas coletivas que classificam o permitido e o proibido e, muitas vezes, podem não coincidir com as lógicas racionais e biomédicas de prevenção (MAKSUD, 2009).

Em relação ao casamento, o sentimento de segurança que gera nas mulheres quando estabelecem esse tipo de vínculo interpessoal faz com elas não se sintam vulnerável à contaminação pelo HIV. 
O retorno ao uso do preservativo é motivado pela vivência de relações sexuais eventuais, onde não se intencione a priori estabelecer um vínculo prolongado e permanente que tenha o amor como premissa.

Nos diversos contextos socioculturais, faixas etárias e nacionalidades, estudos demonstram a intensa relevância das relações afetivas na adoção de comportamentos sexuais protetores. $\mathrm{O}$ uso consistente do preservativo nas relações sexuais é inversamente proporcional à intensidade do vínculo afetivo estabelecido entre os parceiros. As mulheres, quando acreditam estar envolvidas em uma relação afetiva estável, tendo como pilar a confiança, direcionam suas atitudes para atender à vontade do homem e criam a falsa sensação de proteção contra a contaminação pelo HIV, ampliando sua vulnerabilidade (RODRIGUES et al., 2012; MANUEL, 2009).

O conhecimento gerado ao longo da história da epidemia do HIV/Aids permitiu às pessoas elaborarem representações que colocam a prevenção como algo que deve ser compartilhado entre os parceiros. No entanto, ainda é frequente a expressão de saberes que colocam a redução da vulnerabilidade na confiança depositada no outro:

No início eu usava, agora não.[...] É, porque eu peguei confiança nele. [...]Eu confio nele e ele confia em mim. (Maria da Conceição)

Lá no começo, eu usava. Agora não. Porque tem quinze anos já que a gente estamos juntos. (Maria Maria)

De acordo com Tura (2005), as variáveis de opinião evocadas por um grupo de mulheres revelam que o maior tempo de união estável e o baixo nível de escolaridade colocam as mulheres em situação de vulnerabilidade para Aids, pela predominância de ideias apoiadas em construçóes sociais e culturais que demarcam subordinação das mulheres aos homens e pela reprodução de informaçôes divulgadas, sobretudo pela mídia, no inicio da epidemia. Os dados assinalam a necessidade de ações educativas que atendam a especificidades de grupos populacionais e respeitem diferenças socioculturais dos grupos.

Para as mulheres do estudo, o tempo se torna um aliado quando elas elaboram em seu universo simbólico a questão da prevenção ao HIV/Aids em seus relacionamentos estáveis. À medida que o tempo passa e o vínculo se "solidifica", 
significa que uma barreira virtual de proteção se estabelece em suas relações

sexuais. Essa representação evidencia ser desnecessário o uso do preservativo. Abrem mão, portanto, de enfrentarem concretamente a exposição ao vírus da Aids, ao não optarem por esse método de prevenção.

Todavia, nem todas as mulheres entrevistadas elaboram representações acerca da prevenção e da vulnerabilidade ao HIV/Aids. Assumem o risco e são capazes de admitir que não é por desejo do parceiro, mas por vontade própria que não fazem adesão ao uso consistente do preservativo masculino em suas relações sexuais. Têm consciência da grande vulnerabilidade à infecção, mas preferem se expor ao risco do que experienciarem um ato sexual seguro. É eloquente a seguinte manifestação:

Para te falar a verdade nem eu mesmo sempre uso. Vamos ser abertas, eu nem sempre
uso. [...] Eu não gosto. Eles falam no ditado que é igual chupar bala com papel, eu
não acho isso, eu não gosto porque eu sinto que me machuca. Não sei, essa é minha
opinião, eu acho que me machuca, então muito raro, muito raro mesmo. Vou te
falar de verdade, eu sei que tem a doença aí e ela está gritando, mas é muito raro eu
usar. [...] Eu utilizo o anticoncepcional, para não engravidar, não pra não ter o vírus,
infelizmente para não ter nenhuma doença, mas eu não uso mesmo de verdade [...].
(Maria Isabel)

Figueiredo e Ayres (2002) afirmam que é necessário trabalhar as predisposições culturais e os limites materiais para práticas protegidas (vulnerabilidade socioeconômica), assim como incrementar serviços e programas capazes de dar acesso a essas discussóes e aos meios preventivos disponíveis (vulnerabilidade programática), para que, no plano de suas atitudes e práticas pessoais (vulnerabilidade individual), essas mulheres possam de fato se prevenir da infecção pelo HIV.

Embora o preservativo masculino seja o referido nos depoimentos, é oportuno trazer a discussão sobre a estratégia que se apresenta com o preservativo feminino. $\mathrm{O}$ condom feminino representa para as mulheres um maior controle e autonomia sobre seus corpos, além de lhes conferir proteção a uma possível infecção pela via sexual. É a oportunidade de decidir pelo uso do preservativo, sem depender da vontade única e exclusiva do seu parceiro. Permite, portanto, que a mulher tenha o controle, já que pode ser inserido com oito horas de antecedência ao intercurso. Além de apresentar uma vantagem quanto ao aspecto físico, por ser mais resistente que o preservativo masculino, o poliuretano tem menos probabilidade de se romper ou fender em comparação com o látex, substância utilizada na maior parte dos preservativos masculinos, e causar menos reações alérgicas (ONUSIDA, 1998). 
Gazzineli et al. (2005, p. 202) reforçam a ideia de que uma intervenção em Educação e Saúde deve considerar "as representaçōes dos sujeitos, entendidas como noções e modos de pensamento construídos ao lado das trajetórias de vida dos sujeitos, influenciados, por conseguinte, pela experiência coletiva”. Somente assim, ao se observar o sujeito em sua totalidade e complexidade, apreciando valores, conceitos, relações de poder, crenças e sentimentos, poder-se-á almejar maior efetividade em termos de mudança de condutas e práticas sexuais seguras.

Portanto, é na tentativa de dar significado e sentido a suas vidas que essas mulheres encontram nas representaçōes por elas elaboradas respaldo para justificar suas condutas e atitudes diante de suas experiências afetivo-sexuais. Simbolizam no sentimento, na crença, na fidelidade e no amor, o respaldo para viver uma vida compatível e adaptada a seus preceitos construídos coletivamente no contexto ao qual estão inseridas.

\section{Algumas considerações}

$\mathrm{O}$ acesso à informação sobre a Aids mostrou que há um desalinhamento entre as atuais políticas públicas de educação e prevenção ao HIV/Aids e o que realmente está sendo oferecido a essas mulheres em termos de intervenção e promoção de atividades no que se refere ao exercício de suas sexualidades.

Quando se elaboram representaçôes de que o uso do preservativo masculino nas relações sexuais simboliza um mecanismo de prevenção ao HIV/Aids, pressupõese que essas mulheres possuem algum conhecimento sobre o tema lhes permita reduzir suas vulnerabilidades à enfermidade. No entanto, simultaneamente essas mesmas mulheres elaboram representações de que o casamento, o amor, a vida conjugal e o tempo de relacionamento são situações que garantem a imunidade à contaminação pela doença.

Observamos que a questão da Aids faz emergir no universo simbólico dessas mulheres preocupação, incertezas e medo. Entretanto, esses sentimentos não lhes permitem efetivar mecanismos de proteção. Para algumas, as preocupações relacionadas às vivências afetivo-sexuais giram em torno da gravidez e da fidelidade e confiança no parceiro, e neste caso, dispensam o uso consistente do preservativo masculino. De maneira geral, as mulheres entrevistadas não são capazes de incorporar em suas condutas sexuais as informaçôes que expressam ter, embora permaneça o medo de contrair a doença. 
Cabe ressaltar que em nenhum depoimento a camisinha feminina aparece como mecanismo de proteção ao HIV/Aids. Na verdade, esse método de barreira não pertence ao universo das representações dessas mulheres, pois a grande maioria nunca tinha ouvido falar em sua existência. Entretanto, mesmo as que possuíam informação sobre a possibilidade do uso do preservativo feminino nunca tinham visto uma. É, portanto, imperativo que sejam criadas estratégias que tornem mais acessíveis o preservativo feminino para as mulheres em seus diferentes contextos, seja no âmbito público ou privado, através da disponibilização gratuita nos serviços públicos e da redução do preço para quem opta por comprá-lo.

A crença nesse mecanismo vem reafirmar que há um contrassenso entre o que se construiu em termos de programas de educação e prevenção ao HIV/Aids e a forma como as informações estão sendo geradas e absorvidas nos diferentes contextos de vulnerabilidades femininas. Denota-se que trabalhar aspectos educacionais de prevenção, principalmente nas dimensões de aprendizado e comportamento, requer um esforço coletivo, porém localizado e adequado às diferentes necessidades e culturas.

Os resultados apresentados neste estudo, em consonância com as evidências dos dados epidemiológicos dos últimos boletins do PN-DST/Aids, apontam para a permanência da necessidade de formulação de programas, políticas e estratégias de enfrentamento ao HIV/Aids para o segmento feminino. Porém, para sua efetividade, insistimos no urgente reconhecimento das múltiplas dimensões da epidemia que ocorrem em paralelo no Brasil, e também no incentivo e fortalecimento da integração entre os diversos atores sociais, instituições governamentais (envolvendo os níveis federal, estadual e municipal) e nãogovernamentais que atuam no campo da prevenção.

Percebemos que mesmo com o avanço da epidemia entre as mulheres nas últimas duas décadas, principalmente pela via heterossexual, não houve mudança significativa no comportamento sexual de forma a torná-lo mais seguro e consciente no grupo pesquisado. A postura estereotipada e estigmatizante, baseada em critérios subjetivos e aleatórios, que insiste em acompanhar a evolução da Aids nos diversos segmentos, vem contribuindo para o recrudescimento da epidemia no contexto feminino, que historicamente é vítima de desigualdades sociais, econômicas, físicas, culturais e sexuais.

Esta análise nos permite inferir que um dos desafios a serem superados por essa comunidade está associado às estratégias de prevenção, que precisam ser 
repensadas e reelaboradas coletivamente, buscando romper com os entraves que continuam perpetuando lógicas sexuais femininas construídas sob a égide de mitos, preconceitos e diferenças em termos de gênero. Entendemos que os parceiros sexuais irão agir conforme os modelos e regras de condutas norteadas pelos estereótipos da sexualidade de cada cultura.

$\mathrm{O}$ que parece acontecer, no que diz respeito à prevenção das DST/Aids na escola, é que o tema, quando trabalhado, não traz no seu contexto um programa articulado com o cotidiano dos jovens no sentido de entender e compreender a vulnerabilidade ao HIV, mas parece ser desenvolvido pelo compromisso em cumprir um programa estabelecido por orientação vertical. Mesmo que exista a orientação normativa nas formações curriculares, o que temos presenciado é que alguns educadores se sentem preparados e responsáveis por tais conteúdos.

No que diz respeito à relação escola-serviço de saúde, percebemos que há uma parceria que se configura de maneira pouco eficiente entre os atores da escola e os profissionais da unidade básica de saúde (UBS) localizada no bairro onde a escola está situada, pois aquela não parece ser capaz de responder às necessidades de promoção à saúde desse grupo.

Diante dessas observações, um aspecto a ser analisado se refere à formação dos profissionais de saúde, bem como dos docentes, a partir da qualificação em educação sexual. Trabalhar com questôes relacionadas à sexualidade, mais especificamente entre adolescentes e jovens, é uma tarefa por vezes complexa que exige planejamento e execução de uma política pública municipal em consonância com a orientação da política nacional, mas que incorpore programas educativopreventivos adaptados ao contexto local, que abarque a realidade socioeconômica e cultural da população a ser atendida, a estrutura física e humana do serviço e, inclusive e primordialmente, a capacitação e preparação dos profissionais envolvidos na implantação e execução dos programas.

Desse modo, pensar educação para redução da contaminação pelo HIV na escola significa pensar redes de cuidados que envolvam o sistema de saúde, a família, a escola e a comunidade, para que juntos se tornem protagonistas no pensar e no agir para a saúde. E assim, permitir que, no âmbito escolar, professores e alunos desempenhem papéis interrelacionados de saber e poder de forma a reconfigurar o cenário da educação preventiva. ${ }^{1}$ 


\section{Referências}

ABOIM, S. Risco e prevenção do HIV/Aids: uma perspectiva biográfica sobre os comportamentos sexuais em Portugal. Ciênc. saúde coletiva, Rio de Janeiro, v. 17, n. 1, p. 99-112, 2012.

AMARO, S.T. A. A questão da mulher e a Aids: novos olhares e novas tecnologias de prevenção. Revista Saúde e Sociedade, v.14, n.2, p. 89-99, maio-ago, 2005.

ANTUNES, M.C. et al. Diferenças na prevenção da Aids entre homens e mulheres jovens de escolas públicas em São Paulo, SP. Revista Saúde Pública, São Paulo, v. 36, supl. 4, p. 88-95, 2002. Disponível em: <http: //www.scielo.br/ pdf/rsp/v36n4s0/11168. pdf>. Acesso em: 20 maio 2008.

ARRUDA, S., CAVASIN, S. Gênero e prevenção das DST/Aids. In: Coordenação Nacional de DST/Aids. Manual Prevenir é sempre melhor/99. Brasília: Ministério da Saúde, 2000. Disponível em: <http://bvsms.saude.gov.br/bvs/publicacoes/157prevenir.pdf. Acesso em: 10 jan 2010.

AYRES, J.R.C.M. Práticas educativas e prevenção de HIV/Aids: lições aprendidas e desafios atuais. Interface - Comunic, Saúde, Educ, v. 6, n. 11, p. 11-24, 2002.

AZEVEDO, R.L.W. et al. Representações Sociais da adolescente feminina acerca da sexualidade em tempo de Aids. DST - Jornal Brasileiro de Doenças Sexualmente Transmissiveis, Rio de Janeiro, v. 18, n. 3, p. 204-210, 2006. Disponível em: <http:// www.uff.br/dst/revista 1832006/REPRESENTACOES\%20SOCIAIS\%20DA\%20 ADOLESCENCIA\%20FEMININA.pdf>. Acesso em: 10 set 2008.

BARBOSA, R.M.; VILLELA, W.V. A trajetória feminina da Aids. In: PARKER, R.; GALVÃO, J. (org). Quebrando o silêncio: mulheres e Aids no Brasil. Rio de Janeiro: RelumeDumará, 1996.

BARDIN, L. Análise de conteúdo. 5. ed. Lisboa: Edições 70, 2008.

CASTRO, M.G; ABRAMOVAY, M.; SILVA, L.B. Juventudes e Sexualidades. Brasília: UNESCO Brasil, 2004.

BOZON, M.; HEILBORN, M. L. Iniciação à sexualidade: modos de socialização, interações de gênero e trajetórias individuais. In: HEILBORN, M.L. et al. (Org.). $O$ aprendizado da sexualidade: reprodução e trajetórias sociais de jovens brasileiros. Rio de Janeiro: Garamond, 2006.

BRASIL. Ministério da Saúde. Secretaria de Atenção a Saúde. Programa Nacional de DST/Aids. Boletim Epidemiológico Aids e DST. Brasília, ano VIII, n. 01, 2011. Disponível em: http://www.Aids.gov.br/sites/default/files/anexos/publicacao/2011/50652/vers_o_ preliminar_69324.pdf>. Acesso em: $04 \mathrm{dez} 2011$. 
CRUZEIRO, A.L.S. et al. Comportamento sexual de risco: fatores associados ao número de parceiros sexuais e ao uso de preservativo em adolescents. Ciênc. saúde coletiva, Rio de Janeiro, v. 15, supl. 1, p. 1149-1158, 2010.

FIGUEIREDO, R.; AYRES, J.R.C.M. Intervenção comunitária e redução da vulnerabilidade de mulheres às DST/ Aids em São Paulo, SP. Rev. Saúde Pública/USP, São Paulo, v. 36, supl. 4, p. 96-107, 2002. Disponível em: <http://www.scielo.br/pdf/rsp/v36n4s0/11169.pdf>. Acesso em: 13 ago 2008.

FONSECA, M.G. et al. Distribuição social da Aids no Brasil, segundo participação no mercado de trabalho, ocupação e status sócio-econômico dos casos de 1987 a 1998. Cad. Saúde Pública, Rio de Janeiro, v. 19, n.5, p. 1351-1363, set./out., 2003. Disponível em: <http://www. scielo.br/scielo.php? script=sci_arttext\&pid=S0102-311X2003000500013\& $\operatorname{lng}=$ en $\& n r m=$ iso $>$. Acesso em: 13 ago 2008.

GAZZINELLI, M.F. et al. Educação em saúde: conhecimentos, representações sociais e experiências da doença. Cad. Saúde Pública, Rio de Janeiro, v. 21, n.1, p.200-206, 2005.

GOMES, R. et al. Informaçōes e valores de jovens sobre a Aids: avaliação de escolares de três cidades brasileiras. Ciênc. saúde coletiva, Rio de Janeiro, v. 10, n. 2, 2005. Disponível em: <http://www.scielo.br/scielo.php?script=sci_a rttext\&pid=S1413$81232005000200016 \& \operatorname{lng}=$ en \&nrm =iso >. Acesso em: 20 jun 2009.

GRANJEIRO, A.; ESCUDER, M.M.L.; CASTILHO, E.A. Magnitude e tendência da epidemia de Aids em municípios brasileiros de 2002-2006. Rev. Saúde Pública, São Paulo, v. 44,n. 3,p. 430-41, 2010.

JODELET, D (Org.). As representaçôes sociais. Rio de Janeiro: EdUERJ, 2001.

MAKSUD, I. O discurso da prevenção da Aids frente às lógicas sexuais de casais sorodiscordantes: sobre normas e práticas. Physis-Revista de Saúde Coletiva, Rio de Janeiro, v. 19, n. 2, p. 349-369, 2009.

MANUEL, S. Presentes perigosos: dinâmicas de risco de infecção ao HIV/Aids nos relacionamentos de namoro em Maputo. Physis-Revista de Saúde Coletiva, Rio de Janeiro, v. 19, n. 2, p. 371-386, 2009.

MARQUES, S.C.; TYRRELL, M.A.R; OLIVEIRA, D.C. Política de saúde da mulher frente a feminização da Aids. In: PAULA, C.C.; PADOIN, S.M.M.; SCHAURICH, D. (Org.). Aids: o que ainda há para se dito? Santa Maria: EdUFSM, 2007.

MOSCOVICI, S. Representaçôes sociais: investigação em psicologia social. 3. ed. Petrópolis: Vozes, 2003.

ONUSIDA. O preservativo feminino e o SIDA: Ponto de vista da ONUSIDA. Coleção Boas Práticas da ONUSIDA, 1998. Disponível em: <http://www.onu-brasil.org.br/doc/36_O\%20 Preservativo\%20feminino\%20e\%20o\%20SIDA.pdf.> Acesso em: 12 dez 2009. 
PARKER, R.; GALVÃO, J. (Org.). Quebrando o silêncio: mulheres e Aids no Brasil. Rio de

Janeiro: Relume-Dumará, 1996.

RODRIGUES, L.S.A. et al. Vulnerabilidade de mulheres em união heterossexual estável à infecção pelo HIV/Aids: estudo de representações sociais. Rev Esc Enferm USP, Ribeirão Preto, v. 46, n.2, p. 349-355, 2012.

ROUQUAYROL, M.Z.; ALMEIDA, N. Epidemiologia \& Saúde. 6. ed. Rio de Janeiro: MEDSI, 2003.

SZWARCWALD, C.L. et al. A disseminação da epidemia da Aids no Brasil, no período de 1987-1996: uma análise espacial. Cad. Saúde Pública, Rio de Janeiro, v. 16, sup. 1, p. 7-19, 2000. Disponível em: <http://www.scielosp.org/scielo.php?script=sci_arttext\&pi $\mathrm{d}=$ S0102-311X2000000700002\&lng=en \& $\mathrm{nrm}=$ iso $>$. Acesso em: 13 ago 2008.

TAKAHASHI, R.F.; SHIMA, H.; SOUZA, M. Mulher e Aids: perfil de uma população infectada e reflexões sobre suas implicações sociais. Revista Latino Americana de Enfermagem, Ribeirão Preto, v. 6, n. 5, p. 59-65, dez., 1998. Disponível em: <http://www.scielo.br/scielo. php?script $=$ sci_arttext $\&$ pid $=S \quad 010411691998000500008 \& \operatorname{lng}=$ en $\& n r m=i s o>. \quad$ Acesso em: 10 mar 2009.

TOMAZELLI, J.; CZERESNIA, D.; BARCELLOS, C. Distribuição dos casos de Aids em mulheres no Rio de Janeiro, de 1982 a 1997: uma análise espacial. Cad. Saúde Pública, Rio de Janeiro, v. 19, n.4, p. 1049-1061, jul./ago., 2003. Disponível em: <http://www.scielo. br/scielo.php?script=sci_arttext $\&$ pid $=S$ 0102-311X2003000400027\&lng=pt \&nrm =iso $>$. Acesso em: 10 out 2008.

TURA, L.F.R. A Aids: repensando a prevenção. In: TURA, L.F.R.;MOREIRA, A.S.P. Saúde e representações sociais. João Pessoa: EdUFPB; 2005. p. 167-90.

WAGNER, W. Sócio-gênese e características das representações sociais. In: MOREIRA, A. S. P.; OLIVEIRA, D. C. (Org.). Estudos interdisciplinares de representação social. 2 ed. Goiânia: AB, 2000.

XAVIER, I.M. et al. Enfermagem e Aids: saber e paradigma. Revista Latino Americana de Enfermagem, Ribeirão Preto, v. 5, n. 1, p. 65-73, 1997. Disponível em: <http://www.scielo. br/ scielo.php?script $=$ sci_arttext $\&$ pid $=$ S010411691997000100008\&lng $=$ en \&nrm $=$ iso $>$. Acesso em: 10 out 2008.

\section{Nota}

${ }^{1}$ G.A. da Silva contribuiu com a análise dos resultados e elaboração do artigo. V.N. dos Reis contribuiu com a coleta dos dados, análise dos resultados e elaboração do artigo. 


\section{Abstract}

Building paths of knowledge on HIV / AIDS: women on the scene

This qualitative study aimed to identify women's access to information about HIV / AIDS and analyze the factors that guide the adoption of protective measures against HIV / AIDS. Interviews were conducted with 20 women enrolled in evening classes at a public school in Minas Gerais / Brazil, aged between 18 and 55 years. The interviews were analyzed using the technique of thematic content analysis, and grounded in the theoretical framework of Social Representations. We produced two analytical categories: access to information about AIDS and protection mechanisms adopted to reduce vulnerability to HIV infection. Interviewees pointed to school, family, television, friends and health professionals as the main vehicles for obtaining information about AIDS. However, in these spaces and encounters bond is weakened, and defragged inconsistent, not providing access to consistent listening environments, information and reflections. Prevention is focused on the use of condoms. There remains the low power of women to negotiate safe sex, prevailing will of the partner and credibility in love and marriage. The feelings of anxiety, uncertainty and fear generated in these women because of the issue of AIDS cannot allow them to perform protective mechanisms related to changes in sexual behavior in order to make it more safe and aware in the study group.

> Key words: Acquired Immunodeficiency Syndrome; vulnerability; women; disease prevention. 